\title{
Pelatihan Dasar-Dasar Akuntansi bagi Penerima Bea Siswa dari Institut Harta Insan Karimah (IHIK), Jakarta
}

\author{
Wiwiek Mardawiyah Daryanto \\ Sekolah Tinggi Manajemen Ipmi, Jakarta 12750, Indonesia \\ Author E-mail: wiwiek.daryanto@ipmi.ac.id
}

\begin{abstract}
A B S T R A K
Pertumbuhan ekonomi Indonesia yang stabil telah memicu meningkatnya jumlah perusahaan. Seiring dengan meningkatnya jumlah perusahaan, kebutuhan tenaga kerja yang siap di bidangnya telah menjadi prioritas. Di sisi lain, pertumbuhan populasi di Indonesia juga membutuhkan tenaga kerja yang kredibel dan profesional. Oleh karena itu, Presiden Indonesia, Bapak Joko Widodo menyarankan untuk mengembangkan sekolah kejuruan atau sekolah dibidang keterampilan untuk memenuhi kebutuhan tenaga kerja. Situasi ini telah memotivasi Yayasan Harapan Mulya Insani (YAHMI) sebagai pengembang salah satu bank syariah di Indonesia untuk mendirikan lembaga pendidikan kejuruan, yaitu Institut Harta Insan Karimah (IHIK), Jakarta dengan Dasar Dasar Akuntansi sebagai salah satu bagian dari kurikulumnya. Untuk mendukung kebutuhan IHIK, penulis mendapat tugas sebagai penanggung jawab untuk menyiapkan kurikulum dan silabus Dasar Dasar Akuntansi, sekaligus menjadi Pembicara Tunggalnya. Pelatihan ini dilakukan dengan metode kuliah dan metode studi kasus untuk membangun diskusi yang dinamis. Pre-test dan post-test dilakukan dalam pelatihan ini. Pelatihan ini diharapkan bermanfaat untuk meningkatkan pengetahuan dan pemahaman para peserta IHIK tentang pentingnya memahami Dasar Dasar Akuntansi dalam hal mengukur kinerja perusahaan serta kinerja pelanggan nasabah bank tempat mereka akan bekerja dimasa depan.
\end{abstract}

Kata Kunci: Dasar Dasar Akuntansi, Sekolah Kejuruan, YAHMI-HIK.

\section{A B S T R A C T}

A steady growth of Indonesia's economy has triggered the increasing number of enterprises. Along with the increasing number of enterprises, the need of a well prepared manpower in their fields is a priority. The growing population in Indonesia required a credible manpower. Therefore, President of Indonesia, Mr. Joko Widodo suggest to develop the vocational schools to enhance skills and fulfill the need of skilled work force. This situation has motivated the Harapan Mulya Insani Foundation (YAHMI) as a developer of one of syari'ah bank to establish a Vocational School - the Institute of Harta Insan Karimah (HIK) with the Basic Accounting curriculum as one of the subject. To support the institute, the author was responsible to develop the curriculum and syllabus of the Basic Accounting subject, as well as to facilitate the class. Lecturing and case study methods were used as a methodology in this training, in order to develop a dynamic discussion during the training. Pre-test and post test were also carried out. This training is expected to be beneficial to increase the knowledge and understanding of the participants of the IHIK on the importance of understanding Financial Accounting in terms of measuring the performance of the company as well as the performance of their bank customers where they will work in the future.

Keywords: Basic Accounting, Vocational School, YAHMI-HIK. 
Copyright (c) 2020 Authors. This is an open access article distributed under the Creative Commons Attribution License, which permits unrestricted use, distribution, and reproduction in any medium, provided the original work is properly cited.

\section{PENDAHULUAN}

Saat ini, perekonomian di Indonesia telah mengalami peningkatan yang stabil. Hal ini dibuktikan dengan data Biro Pusat Statistik Indonesia (2015) yang menyatakan bahwa Indonesia berpotensi menambah empat juta hingga enam juta perusahaan selama dekade terakhir, dari 2006 hingga 2016, sehingga jumlah total perusahaan yang beroperasi di negara ini menjadi sejumlah 26 juta hingga 29 juta. Berkembangnya jumlah perusahaan menuntut kebutuhan tenaga kerja yang terampil dibidangnya. Dilain pihak, pertumbuhan penduduk yang tinggi juga memerlukan lapangan kerja bagi angkatan kerja yang tersedia. Indonesia merupakan negara dengan jumlah penduduk ke empat tertinggi di dunia setelah Cina, India, dan Amerika Serikat. Menurut data Statitik Indonesia 2018, jumlah penduduk Indonesia berjumlah 237 juta pada tahun 2010 dan diestimasikan akan mencapai 261 juta pada tahun 2017 (Biro Pusat Statisik Indonesia, 2017). Oleh karena itu, saat ini Presiden Joko Widodo merancangkan berdirinya sekolah-sekolah dibidang keterampilan, atau sekolah vokasi untuk memenuhi kebutuhan kerja. Situasi ini memotivasi Yayasan Harapan Mulya Insani (YAHMI) untuk mendirikan lembaga pendidikan dan pelatihan syariah berkualitas di bidang jasa keuangan bank dan non-bank, serta koperasi, bernama Institut Harta Insan Karimah (IHIK). Dari enam mata kuliah yang dimasukkan ke dalam kurikulumnya, salah satunya adalah Dasar Dasar Akuntansi dan dijadwalkan selama dua hari yaitu 28 dan 30 Oktober, 2019. Surat penunjukan penulis sebagai penyusun silabus mata kuliah tersebut dan sebagai pembicara tunggalnya dapat dilihat pada Gambar 1.

Peserta didik yang lulus seleksi pada angkatan pertama ini berjumlah 20 (dua puluh) orang seperti terlihat pada Tabel 1 .

Demikian pula sertifikat sebagai Pembicara Tunggal dapat dilihat pada Gambar 3.

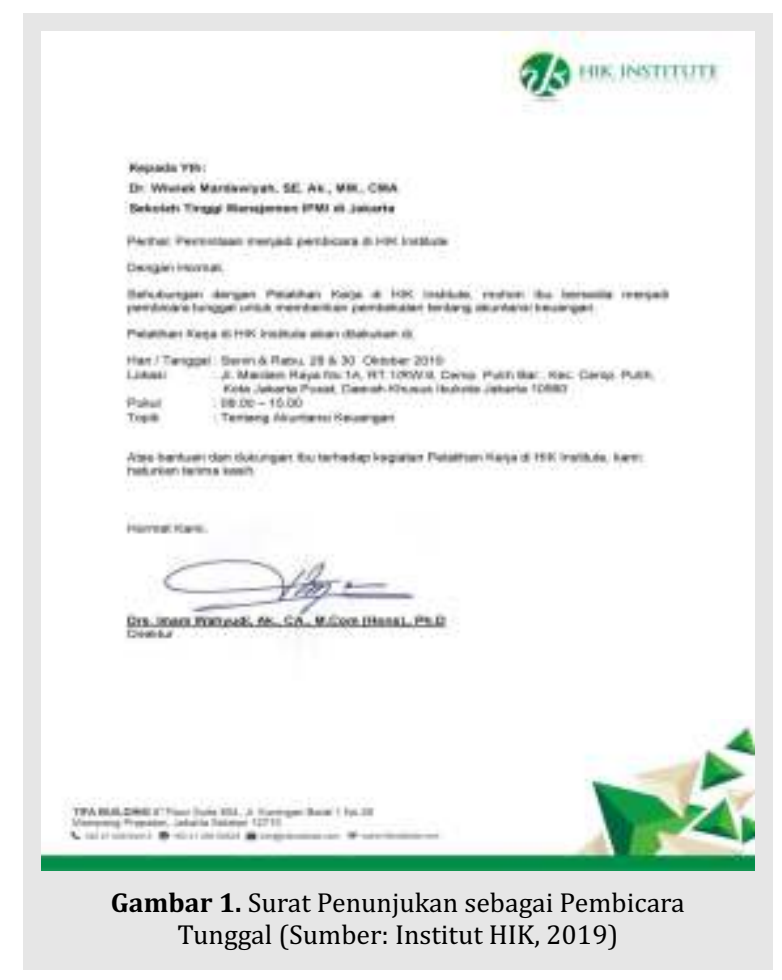

Tabel 1. Daftar Peserta Didik Pelatihan Dasar-Dasar Akuntansi pada Tanggal 28 dan 30 Oktober, 2019

\begin{tabular}{ccc}
\hline No & NIM & Nama \\
\hline 1 & 190010001 & Sunita Damayanti \\
\hline 2 & 190010002 & Firmawati Putri Pradini \\
\hline 3 & 190010003 & Noor Qurrota A'yun \\
\hline 4 & 190010004 & Nisrina Qatrunnada \\
\hline 5 & 190010005 & Sahrul Muhamad Arif \\
\hline 6 & 190010006 & Sri Putri Aditya \\
\hline 7 & 190010007 & Ridha Adelina Nabila \\
\hline 8 & 190010008 & Rohanda \\
\hline 9 & 190010009 & Jerry Brilianda \\
\hline 10 & 1900100010 & Rafli Nurudin \\
\hline 11 & 1900100011 & Dyah Bentang Kusuma P \\
\hline 12 & 1900100012 & Larasati Widya Gunadi \\
\hline 13 & 1900100013 & Tassya Indah Kartika \\
\hline 14 & 1900100014 & Adjri Agustni \\
\hline 15 & 1900100015 & Rohanna Febriana Firmansyah \\
\hline 16 & 1900100016 & Answar Gusnedi \\
\hline 17 & 1900100017 & Sukma Indra Pamungkas \\
\hline 18 & 1900100018 & Agus Abu Bakar \\
\hline 19 & 1900100019 & Anton Suherman \\
\hline 20 & 1900100020 & Maulana Hasanudin \\
\hline
\end{tabular}

Sumber: Institut HIK, 2019 


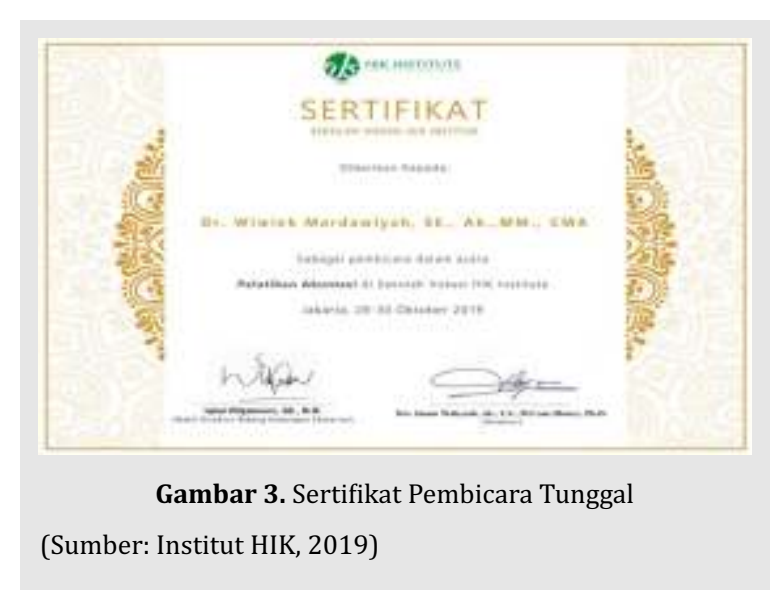

Latar Belakang Yayasan Harapan Mulya Insani (YAHMI)

YAHMI adalah suatu yayasan yang didirikan untuk untuk menaungi berdirinya sejumlah bank syariah, bernama Bank Harta Insan Kharimah di Indonesia. YAHMI pertama kali didirikan pada tanggal 25 bulan Juli 1990 dengan Akta Notaris Ny. Tetty Subroto Nomor 64, dengan kekayaan awal sebesar Rp60.000.000 (enam puluh juta rupiah). Namun, pada awal pendiriannya, Yayasan ini belum didaftarkan ke Kementerian Hukum dan HAM. Pendiri YAHMI merupakan tokoh-tokoh HMI Komisariat Fakultas Ekonomi Universitas Gajah Mada yang dalam karirnya telah mencapai puncak yang sangat membanggakan bagi generasi penerus. Pada tanggal 4 Maret 2015 YAHMI telah mendapatkan pengakuan sebagai Badan Hukum yang sah dengan keputusan Menteri Hukum dan Hak Asasi Manusia Republik Indonesia Nomor AHU-0003239.AH.01.Tahun 2015.

\section{Latar Belakang Institut Harta Insan Karimah (IHIK)}

Institut Harta Insan Karimah (HIK) didirikan pada tanggal 12 April 2019 di Jakarta oleh Yayasan Harapan Mulya Insani (YAHMI) dengan maksud untuk mengembalikan dana hibah ke Bank Perkreditan Rakyat Syariah (BPRS) HIK grup dalam bentuk menyediakan Sumber Daya Manusia (SDM) yang siap pakai dan dapat mengaplikasikan ilmunya pada tataran operasional perbankan syariah. Untuk mencapai tujuan tersebut maka didirikanlah Institut HIK, dengan Visi, Misi, dan Tujuan seperti diuraikan di bawah ini.

\section{Visi Pendirian Institut Harta Insan Karimah (IHIK)}

- Menjadi lembaga pendidikan dan pelatihan syariah berkualitas di bidang jasa keuangan bank dan non-bank, serta koperasi.

\section{Misi Pendirian Institut Harta Insan Karimah (IHIK)}

- Mendidik dan melatih sumber daya manusia yang syar'i, siap kerja dengan kemampuan yang terampil dan profesional.

- Menyiapkan dan menyediakan sumber daya insani yang mampu membuat jaringan bisnis dengan memanfaatkan informasi komuni tek dan komunitas.

\section{Tujuan Pendirian Institut Harta Insan Karimah (IHIK)}

- Mencetak tenaga perbankan, lembaga keuangan non-bank dan koperasi syariah di tingkat pelaksana yang siap pakai.

Kurikulum IHIK ini dirancang selama 6 (enam) minggu, dengan mata kuliah per minggu, dari minggu pertama hingga minggu ke enam dengan tatap muka di kelas selama dua hari per minggu, sebagai berikut:

1. Ke-HIK-an dan Soft Skill.

2. Fiqih Muamalah.

3. Arsitektur Perbankan Indonesia dan Perkembangan Teknologi Terkait.

4. Dasar Dasar Akuntansi.

5. Produk dan Jasa Keuangan Syariah (Siklus Pendanaan).

6. Produk dan Jasa Keuangan Syariah (Siklus Pembiayaan).

\section{DEFINISI AKUNTANSI KEUANGAN}

Akuntansi mencakup semua kegiatan dalam berorganisasi, seperti kegiatan beroperasi, pendanaan, dan investasi. Dalam semua kegiatan, penekanan utamanya adalah untuk menggunakan informasi akuntansi dalam proses pengambilan keputusan. Manajer dalam organisasi menggunakan informasi akuntansi sebagai pegangan dalam membuat keputusan yang mempengaruhi organisasi. Terdapat banyak 
pendapat penulis dan organisasi dalam mendefinisikan akuntansi, di antara nya sebagai berikut:

1. Definisi akuntansi yg dikembangkan oleh Komite Asosiasi Akuntansi Amerika sebagaimana didefinisikan menjadi proses mengidentifikasi, mengukur, \& mengkomunikasikan liputan ekonomi buat memungkinkan penilaian \& keputusan yang diinformasikan oleh pengguna liputan (Anthony, etal, 2011).

2. Akuntansi adalah sistem berita. Akuntansi mengukur kegiatan bisnis, memasak data sebagai laporan, \& mengkomunikasikan hasil pada orang-orang. Akuntansi merupakan "bahasa bisnis". Semakin baik Anda memahami bahasa, semakin baik Anda bisa mengelola keuangan Anda (Horngren et al, 2008).

3. Akuntansi merupakan sistem berita yg mengidentifikasi, mencatat, dan mengkomunikasikan peristiwa ekonomi suatu organisasi kepada pengguna yg tertarik. Banyak orang mempunyai minat untuk mengetahui tentang aktivitas bisnis yang sedang berlangsung. Orang-orang ini merupakan pengguna warta akuntansi (Weygandt et al, 2004).

4. Akuntansi bisa didefinisikan sebagai sistem kabar yang menaruh laporan kepada para pemangku kepentingan tentang kegiatan ekonomi dan syarat bisnis (Warren et.Al, 2002).

5. Akuntansi adalah sistem liputan yg mengukur kegiatan bisnis, memproses berita menjadi laporan, dan mengkomunikasikan hasilnya kepada pengambil keputusan (Horngren et al, 2005).

\section{BEA SISWA DAN PERSYARATAN PESERTA}

Pada termin awal, IHIK memberikan beasiswa didik kepada peserta yang lulus seleksi pada bentuk pembebasan biaya sekolah dan akomodasi selama periode pelatihan. Adapun persyaratan penerimaan peserta adalah menjadi berikut:

1. Beragama Islam.

2. Lulusan Sekolah Menengan Umum atau Pondok
Pesantren \& sederajat lulusan tahun 2017 sampai menggunakan 2019.

3. Nilai rata-rata rapor tahun terakhir minimal buat pesantren 6,5 \& buat non-pesantren 7,0.

4. Bersedia tidak menikah selama masa pendidikan.

5. Bagi peserta yang dinyatakan lulus harus bersedia ditempatkan pada jaringan kantor BPRS HIK Grup, yaitu Bandung, Bekasi, Tanggerang, Yogyakarta, Solo, Makasar, dan Tegal.

6. Bersedia menjalani ikatan dinas selama 3 tahun sejak menuntaskan pendidikan dan dinyatakan lulus.

Untuk angkatan pertama yang lulus seleksi sebanyak 20 (dua puluh) orang tertera dalam Tabel 1. Perkuliahan dimulai pada bulan September 2019.

\section{TUJUAN DAN MANFAAT PELAKSANAAN}

Pelatihan ini dirancang agar para peserta didik yang mempunyai latar belakang yang beragam, baik pendidikan dan posisi dalam pekerjaannya lebih memahami tentang Dasar Dasar Akuntansi dengan tujuan sebagai berikut:

1. Mempelajari elemen-elemen dasar dasar akuntansi.

2. Mempelajari fakta keuangan yang relevan untuk pengambilan keputusan manajemen.

3. Mempraktekkan bagaimana menggunakan warta keuangan buat keputusan-keputusan manajemen.

4. Memahami konsep-konsep dasar laporan keuangan, baik laporan laba-rugi maupun neraca.

5. Memahami dan menyadari secara lebih efektif bagaimana mengelola modal kerja dan investasi jangka panjang.

6. Memiliki ketrampilan spesifik di bidang akuntansi, mulai menurut pencatatan buktibukti keuangan sampai penyajiannya dalam laporan keuangan perusahaan.

Diharapkan para peserta didik dapat memanfaatkan pemahaman mengenai Akuntansi Keuangan antara lain untuk: 
1. Memiliki ketrampilan pada pencatatan transaksi-transaksi keuangan sampai dengan penyajian laporan keuangan secara periodik.

2. Memahami laporan keuangan, rasio-rasio keuangan, dan aturan perusahaan.

3. Meningkatkan pengertian pentingnya peranan manager keuangan

4. Memahami secara menyeluruh praktek-praktek dan teknik-teknik analisa keuangan memakai situasi rill yg terjadi waktu ini.

5. Mempelajari penggunaan keterangan keuangan pada pengambilan keputusan manajemen.

6. Meningkatkan dominasi terhadap bahasa bisnis.

7. Meningkatkan kemampuan berkomunikasi dengan para eksekutif keuangan, bertanya dengan pertanyaan yang rasional, dan mengerti bagaimana wajib menanggapinya.

\section{METODE PELAKSANAAN}

Sebelum melaksanakan kegiatan pelatihan Akuntansi Keuangan ini, penulis atau fasilitator melakukan berbagai persiapan diantaranya:

1. Melakukan studi pustaka tentang Dasar Dasar Akuntansi sebagai alat pengambilan keputusan dan merupakan strategi dalam meningkatkan kinerja perusahaan.

2. Menentukan dan mempersiapkan materi dan bahan untuk pelatihan Dasar Dasar Akuntansi dalam meningkatkan kinerja perusahaan.

Kegiatan pelatihan ini dilakukan dengan metode pemberian kuliah dan diikuti dengan metode studi kasus untuk membangun dinamika diskusi antara fasilitator dan peserta didik, maupun diantara peserta didik itu sendiri. Dan juga dilakukan ujian untuk menilai keberhasilan pelatihan dan pendalaman materinya melalui pretest maupun post-test. Hasilnya cukup memuaskan.

\section{HASIL DAN PEMBAHASAN}

Berdasarkan hasil dari pre-test dan post-test yang diberikan sebelum dan sesudah mengikuti pelatihan dan pengamatan langsung selama kegiatan pelatihan ini berlangsung memberikan hasil sebagai berikut:
1. Program pelatihan telah berhasil meningkatkan pengetahuan dan pemahaman peserta didik tentang pentingnya memahami Dasar Dasar Akuntansi dalam bentuk penyusunan dan interpretasi terhadap laporan keuangan.

2. Ilmu yang diperoleh diharapkan telah meningkatkan kompetensi dan produktivitas peserta untuk bekerja di kemudian hari.

Beberapa faktor yang mendukung terlaksananya kegiatan pelatihan ini diantaranya adalah adanya minat yang besar dan antusiasme yang tinggi dari peserta didik selama kegiatan, sehingga kegiatan berlangsung dengan lancar dan efektif. Disamping itu, para peserta berharap akan adanya kesempatan untuk bekerja di bankbank syariah dibawah naungan YAHMI. Dari hasil analisa evaluasi setelah program pelatihan berlangsung dapat diketahui bahwa faktor penghambat di mata peserta adalah disebabkan karena keterbatasan waktu pelatihan. Ini menunjukkan bahwa para peserta mengharapkan akan adanya modul-modul tambahan di kemudian hari.

Untuk mengetahui keberhasilan dari pelaksanaan pelatihan ini dilakukan pre-test sebelum pelatihan di mulai, dan juga dilakukan post-test setelah pelatihan usai. Hasil dari post test bila dibandingkan dengan pre test menunjukkan perkembangan yang menggembirakan. Ini menggambarkan bahwa para peserta dapat memahami proses-proses pembelajaran selama program pelatihan berlangsung. Untuk dapat melihat antusiasme para peserta, selama pelatihan berlangsung telah dilakukan pengambilan foto. Berikut ini dapat diobservasi ketekunan para peserta melalui foto-foto kegiatan selama masa pelatihan yang dapat dilihat pada Gambar 4.

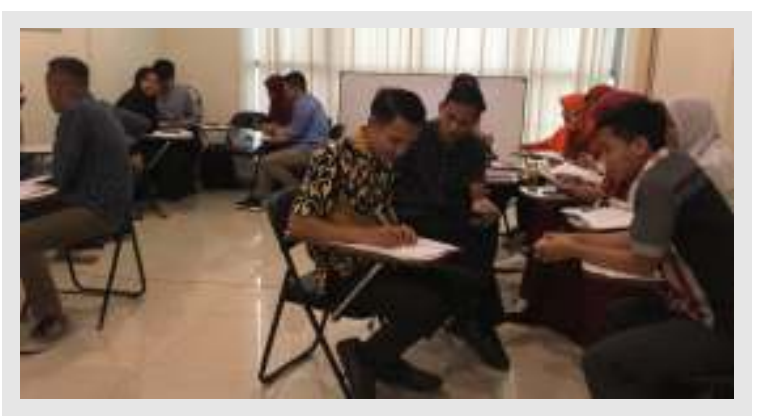




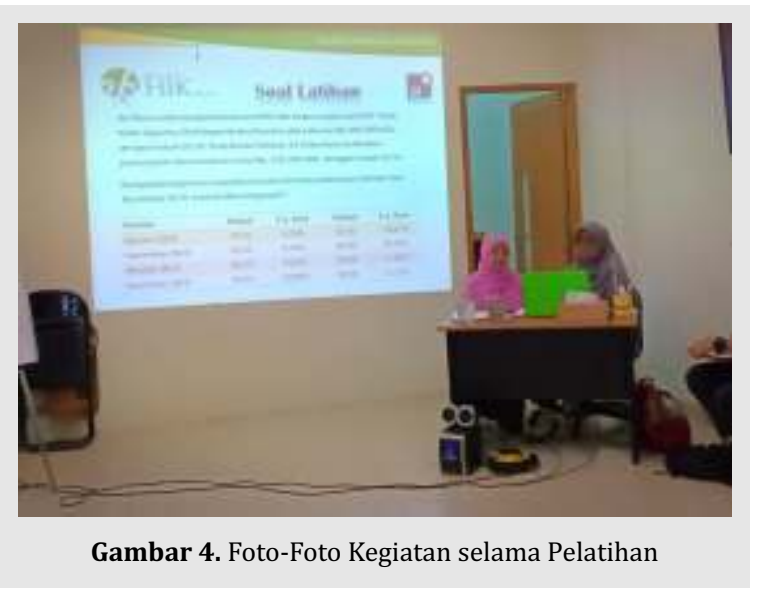

\section{KESIMPULAN DAN SARAN}

Kesimpulan dan SaranBerdasarkan pembahasan di atas maka dapat disimpulkan bahwa DasarDasar Akuntansi sangat diperlukan untuk menghasilkan suatu laporan keuangan perusahaan yang merupakan rapor keberhasilan suatu usaha dan sebagai pedoman untuk mengambil keputusan. Melalui pemahaman terhadap laporan keuangan perusahaan akan dapat dinilai kemampuan perusahaan untuk memenuhi kewajiban-kewajiban jangka pendeknya, maupun jangka panjangnya, struktur modal perusahaan, distribusi besarnya aktiva, keefektifan penggunaan aktiva, hasil usaha atau pendapatan yang berhasil dicapai, beban-beban yang harus dibayar, serta nilai-nilai buku tiap lembar saham perusahaan yang bersangkutan.

Setelah mengikuti kegiatan pelatihan ini para peserta diharapkan mampu meningkatkan pengetahuan dan pemahaman mengenai pentingnya memahami Dasar Dasar Akuntansi dalam hal mengukur kinerja perusahaan, termasuk kinerja nasabah-nasabah bank dimana mereka akan bekerja di masa yang akan datang.

Mengingat besarnya manfaat dari kegiatan pelatihan Dasar Dasar Akuntansi dalam meningkatkan kinerja perusahaan, maka selanjutnya perlu adanya pelatihan yang menyeluruh untuk seluruh karyawan, khususnya bagi karyawan BPRS HIK di seluruh Indonesia. Hal ini diusulkan, mengingat pentingnya peran pelatihan Dasar Dasar Akuntansi sebagai bekal pengetahuan bagi karyawan BPRS HIK. Pelatihan Akuntansi ini juga perlu ditingkatkan ke tingkat berikutnya, seperti Akuntansi Intermediate; Akuntansi Manajerial; dan Akuntansi Lanjutan.

\section{DAFTAR PUSTAKA}

Anthony, R.N; Reece, J.S; and Hertenstein, J.H. (2011). Accounting: Text and Cases,13th Edition.Irwin, Chicago.

Badan Pusat Statistik (2015). Sensus Ekonomi 2014, Jakarta: Badan Pusat Statistik. Available from:https://www.bps.go.id/publication/2014/05/05/8d2c08d9d41aa8c02fad22e7/statistikindonesia-2014.html

Badan Pusat Statistik (2017). Statistik Indonesia 2018, Jakarta: Badan Pusat Statistik. Available from:https://www.bps.go.id/publication/2018/07/03/5a963c1ea9b0fed6497d0845/statistikindonesia-2018.html

Horngren, Charles T., Harrison Jr., Walter T., Bamber, Linda Smith. (2005). Accounting (6th ed.). Englewood Cliffs: Pearson Prentice-Hall.

Horngren, Charles T., Harrison Jr., Walter T.. (2008). Financial accounting (7th ed.). Upper Saddle River: Pearson Education International.

Warren, Carl S., Reeve, James M., Fess, Philip E.. (2002). Accounting (20th ed.). Australia: Thompson SouthWestern.

Weygandt, Jerry J., Kieso, Donald E., Kimmel, Paul D(2004). Financial accounting tools for business decision making (3rded). Hoboken: John Wiley \& Sons, Inc.

YAHMI - Yayasan Harapan Mulya Insani (n.d). Available from: 